\title{
Laudatio
}

\section{Joel D. Kopple: Corresponding Member of the Gesellschaft für Nephrologie}

Joel D. Kopple, born in Chicago in 1938, received his MD from the University of Illinois in 1962. In 1963, he moved to the UCLA School of Medicine, and was promoted to Full Professor of Medicine and Public Health in 1978. Since 1982, he is chief of the Division of Nephrology and Hypertension at the Harbor-UCLA Medical Center, Torrance, CA.

The scientific oeuvre of Joel D. Kopple ranges from basic science to clinical research and reflects the broad interest of this brilliant scientist. Specifically, Joel D. Kopple has made seminal contributions to the metabolism and nutritional status of uremic patients, and it is fair to say that he is the internationally leading scientist in this important area of research. This success is based on his outstanding capability to utilize biochemical and physiological expertise for the understanding and solving of clinical problems.

His broad knowledge made Joel D. Kopple a valuable member of the editorial boards of several important journals including Nephron, Mineral \& Electrolyte Metabolism, Clinical Nephrology, American Journal of Nephrology, Seminars in Dialysis and Journal of Renal Nutrition.

Beyond his scientific achievements, Joel D. Kopple has served the scientific community as president of several Societies, i.e. the National Kidney Foundation, the Council of American Kidney Societies, the American Society for Parenteral and Enteral Nutrition, the International Society for Renal Nutrition and Metabolism, and he has been elected into various further functions of a number of Scientific Societies including the American Society of Nephrology and the International Society of Nephrology.

Joel D. Kopple received a great number of awards for his scientific achievements, including the President's Award of the National Kidney Foundation, the Louis Pasteur Medal and Award of the University of Strasbourg, the

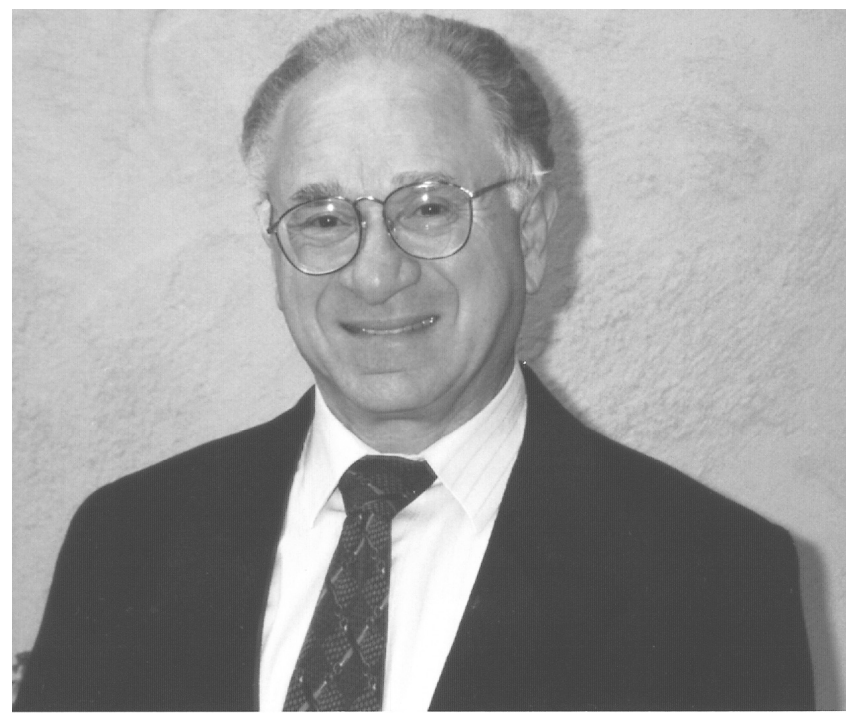

David M. Hume Memorial Award of the National Kidney Foundation, the Thomas Addis Medal of the International Society for Renal Nutrition and Metabolism and the honorary doctorate from the Sfarik University. He is honorary member of several societies for Nephrology and for Internal Medicine.

Beyond his scientific excellence, Joel D. Kopple impresses by his broad knowledge and wisdom. Many members of the Gesellschaft für Nephrology have been inspired and still continue to be inspired by his thoughts. With the Corresponding Membership, the Gesellschaft für Nephrologie is proud to honor this outstanding scientist and man.

Florian Lang, Tübingen

\begin{tabular}{ll}
\hline KARGER & ( ) 2000 S. Karger AG, Basel \\
1420-4096/00/0235\$17.50/0 \\
$\begin{array}{l}\text { Fax +41 61 306 12 34 } \\
\text { wwail karger@karger.ch }\end{array}$ & $\begin{array}{l}\text { Accessible online at: } \\
\text { http://BioMedNet.com/karger }\end{array}$
\end{tabular}

Prof. Dr. Florian Lang

Physiologisches Institut der

Universität Tübingen

Gmelinstrasse 5

D-72076 Tübingen (Germany) 